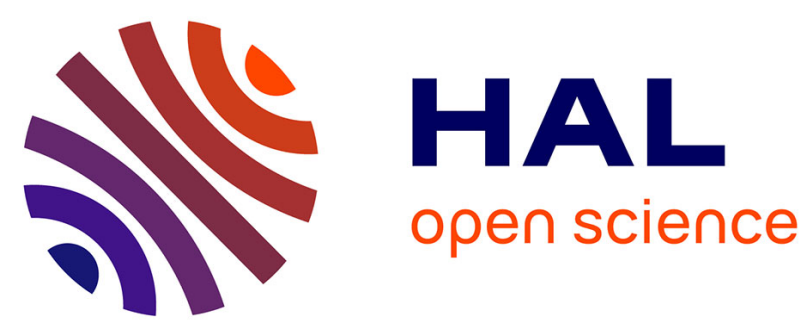

\title{
Identifying the driving processes of Diesel spray injection through mixture fraction and velocity field measurements at ECN Spray A
}

Louis-Marie Malbec, Gilles M Bruneaux, Bart Somers, Christine Mounaïm-Rousselle, Lyle M Pickett

\section{To cite this version:}

Louis-Marie Malbec, Gilles M Bruneaux, Bart Somers, Christine Mounaïm-Rousselle, Lyle M Pickett. Identifying the driving processes of Diesel spray injection through mixture fraction and velocity field measurements at ECN Spray A. SAE Technical Paper, 2020, pp.SAE 2020-01-0831. 10.4271/202001-0831 . hal-02877268

\section{HAL Id: hal-02877268 \\ https://hal-ifp.archives-ouvertes.fr/hal-02877268}

Submitted on 29 Jun 2020

HAL is a multi-disciplinary open access archive for the deposit and dissemination of scientific research documents, whether they are published or not. The documents may come from teaching and research institutions in France or abroad, or from public or private research centers.
L'archive ouverte pluridisciplinaire HAL, est destinée au dépôt et à la diffusion de documents scientifiques de niveau recherche, publiés ou non, émanant des établissements d'enseignement et de recherche français ou étrangers, des laboratoires publics ou privés. 


\section{Identifying the driving processes of Diesel spray injection through mixture fraction and velocity field measurements at ECN Spray A}

\begin{abstract}
Diesel spray mixture formation is investigated at target conditions using multiple diagnostics and laboratories. High-speed Particle Image Velocimetry (PIV) is used to measure the velocity field inside and outside the jet simultaneously with a new frame straddling synchronization scheme. The PIV measurements are carried out in the Engine Combustion Network Spray A target conditions, enabling direct comparisons with mixture fraction measurements previously performed in the same conditions, and forming a unique database at diesel conditions. A 1D spray model, based upon mass and momentum exchange between axial control volumes and nearGaussian velocity and mixture fraction profiles is evaluated against the data. The 1D spray model quantitatively predicts the main spray characteristics (average mixture fraction and velocity fields) within the measurement uncertainty for a wide range of parametric variations, verifying that a Diesel spray becomes momentum controlled and has a Gaussian profile. A required input to the model is the jet angle, which is obtained experimentally. Although an expected result for a gas jet, this is the first time that combined datasets of velocity and mixture fraction have been obtained in vaporizing sprays at Diesel conditions ( $900 \mathrm{~K}, 60 \mathrm{bar})$. Finally, these results show that a consistent database can be built using advanced diagnostics performed by different institutions when the boundary conditions are well known as prescribed by the ECN Spray A framework.
\end{abstract}

\section{Introduction}

Designing fuel-efficient, low-exhaust-emission Diesel engines requires a detailed understanding of the physical phenomena occurring in the combustion chamber. One of the decisive processes in conventional direct-injection Diesel engines is the mixing between air and fuel. Indeed, for fixed operating conditions (cetane number, temperature, density, EGR rate), the turbulent mixing rate is a key factor governing the chemistry and affecting different stages of the combustion process as:

- Ignition delay and premixed flame: an increase of the mixing rate will lead to a decrease of the ignition delay, and thus will affect the premixed flame process and the level of noise

- Controlled diffusion: various studies, in combustion vessels [1-3] or in engines [4-9], have shown a correlation between the fuel-air ratio at lift-off length and the amount of soot produced in the spray. Lowering the fuel-air ratio by enhancing the mixing rate is thus desirable in order to decrease soot emissions;

- End of injection: Musculus [10] has observed a rapid decrease of mixture fraction near the nozzle tip after the end of injection, later explained by the concept of an "entrainment wave" [11]. This entrainment wave has now been observed experimentally [12], and it may affect unburned hydrocarbon emissions (UHC) via over- or under- mixing. It can also have an effect on the ignition delay if the End Of Injection (EOI) occurs before ignition [13].

The fuel-air mixing processes of vaporizing Diesel sprays have been investigated by a combination of experiments and computational efforts [14-21], trying to define the role of large and small scale structures in the air entrainment processes. In [14, 16, 20, 21], air entrainment is supposed to be caused by air engulfment in large structures. However, in [17-19], small scale turbulent structures are described as the main process controlling air entrainment. An approach combining small and large scales has been proposed in [15]. In spite of the uncertainty in the mechanisms governing air entrainment, simplistic models for mass and momentum exchange in one dimension along the axis of the spray have been proposed to compute the spray development and the air-fuel mixing [22, 23]. Although these models show good abilities to predict the behavior of a Diesel spray in terms of vapor penetration, the underlying assumptions concerning mixing processes have not been experimentally validated. Such a validation is of high priority, since it can confirm or expose the hypothesis of the 1D model concerning the physical phenomena driving the mixing process.

However, the study of the air entrainment in Diesel jets is of high complexity because of the strong coupling that exist between the contributing mechanisms, such as fuel evaporation, turbulence, small scale mixing, and so forth. Ideally, the coupled quantitative measurement of several parameters such as flow velocities and mixing characteristics would be required. These types of measurements are routine in ambient temperature gas jet environments [24], but remain challenging in a Diesel environment, where the high-pressure, high-temperature gradients and the presence of liquid droplets make the application of optical diagnostics more complicated.

To overcome these difficulties, a group of international laboratories joined efforts to form the Engine Combustion Network (ECN, see website https://ecn.sandia.gov/) to build a collaborative database on engine combustion, and in particular on Diesel sprays. The ECN seeks to bring a better understanding of the physical phenomena occurring during injection and combustion, and to provide a unique and complete database for CFD model validation. One of the main requirements for the construction of such a database is the definition of a common target condition that needs to be reproduced by each participating institution to leverage research capabilities and advanced diagnostics of all ECN participants. The first target condition, called Spray A has been defined with detailed ambient ( $900 \mathrm{~K}, 60 \mathrm{bar}, 22.8 \mathrm{~kg} / \mathrm{m} 3,0 \%$ or $15 \%$ oxygen) and injector (common rail, 1500 bar, KS1.5/86 nozzle, 0.090-mm orifice diameter, n-dodecane, $363 \mathrm{~K}$ ) conditions [25]. Establishing and improving Spray A conditions in unique facilities throughout the world represents a major step forward in the establishment of highquality, quantitative data sets for engine spray combustion. Boundary 
conditions and basic Spray A characterization based on standardized diagnostics have been extensively compared [26-28], showing the ability of different laboratories to reproduce the same boundary conditions. Based on this preliminary validation, mixture fraction fields have been obtained by Sandia National Laboratories (SNL) [29], and velocity fields by IFPEN [27], for identical boundary conditions and with nominally identical injectors. Therefore, the velocity and mixture fraction fields, although obtained in 2 different facilities, should be representative of the same mixing process. This assumption needs to be verified, in order to validate the scientific approach of the ECN network

This requires the use of modeling. CFD codes could be used to answer this question, but at the cost of a careful, and therefore long, calibration of the turbulence model, and of a long computational time. The 1D spray model mentioned earlier [11, 22, 23, 29, 30], has proven to accurately match the spray tip penetration with respect to time. It is based on assumptions (see section "Description of the 1D model" for details) that induce specific velocity and mixture fraction fields within the spray. However, those estimated fields have so far not been compared to experimental ones, mainly because the required data for such a comparison, velocity and mixture fraction fields, are difficult to obtain and are therefore rare. Here, the environment of the ECN provides the opportunity to have access to these data for similar boundary conditions and thus to validate the behavior of the 1D spray model against experimental data. This is the goal of the present paper.

As an answer to the above questions, the objectives of this work are:

- a validation of the 1D spray model against experimental data (velocity and mixture fraction fields in the spray). This step will validate the underlying assumptions concerning the physical phenomena leading the mixing processes;

- a validation of the ECN scientific approach, by the comparison of the velocity and mixture fraction fields within the spray. If proven successful, results obtained by different institutions may be combined to form a unique and comprehensive database for model validation. This comparison will be performed using the 1D spray model.

The experimental apparatus and experimental techniques used to obtain the velocity fields are first presented (mixture fraction fields have been obtained by Sandia, thus the experimental setup is available in [29] and will not be presented here). Then, the experimental results are analyzed to provide information on the driving processes of mixture formation, and to validate the assumptions of the 1D spray model. At last, a comparison of the velocity and mixture fraction fields is performed in order to assess whether they can be combined in a unique database that can be used for CFD model validation..

\section{Experimental apparatus and methods}

\section{IFPEN Constant-Volume Preburn chamber}

Within this work, the IFPEN Constant-Volume Preburn (Figure 2) chamber is used to study fuel sprays at engine-relevant conditions. The ambient pressure, temperature and species at the time of injection are varied by igniting a premixed combustible-gas mixture that burns to completion. Following the spark-ignited, premixed combustion, the combustion products cool over a relatively long time $(\sim 1 \mathrm{~s})$, due to heat transfer to the vessel walls and as a result the

Page 2 of 12 vessel pressure slowly decreases. When the desired pressure and temperature are reached, the diesel fuel injector is triggered and fuel injection occurs. More detailed information can be found in [25, 27].
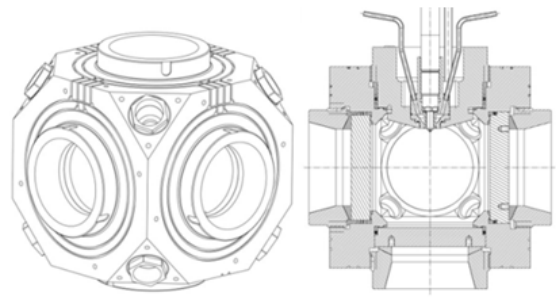

Inner width : $125 \mathrm{~mm}$ Volume : $1400 \mathrm{~cm}^{3}$ Windows diameter : $80 \mathrm{~mm}$ Wall temperature: $473 \mathrm{~K}$ Nozzle tip protrusion: $3 \mathrm{~mm}$ 4 sparks plugs in the lower corners

Figure 1 - Global view (left), cross-section (center, with an injector mounted on top), and characteristics (right) of IFPEN constant volume vessel

\section{Boundary conditions}

Non-reacting spray A boundary conditions have been targeted for this work, along with two mono-parametric variations of the injection pressure (1000bar instead of 1500bar), and of the ambient density $(15.2 \mathrm{~kg} / \mathrm{m} 3$ instead of $22.8 \mathrm{~kg} / \mathrm{m} 3)$. These variations have been selected because they directly affect the mixing processes. ECN injector number 210678-aged has been used. All the boundary conditions are summarized in Table 1, both for the IFPEN setup and for the Sandia one. The values in brackets represent the monoparametric variations performed around the standard spray A conditions. Even if the ECN injectors are nominally identical in order to allow different laboratories to perform experimental campaigns simultaneously, some differences in the orifice diameter and in the behavior such as the mass flow rates and momentum have been observed. As detailed in [31], it leads to differences in spray development, ignition and combustion process. These differences can be explained either by slightly different machining at production, or by an alteration of the orifice surface of the injector caused by its utilization, as highlighted in [32]. For the present study, it is worth mentioning that injectors 210677 and 210678-aged show different values for mass flow rate and momentum, which are likely to impact the mixing processes. These flow characteristics are summarized in Table 1. It must be noted that the momentum measurement for injector 210678-aged was performed while it had already been used for a while. Aging (oxidation of nozzle to reduce diameter and lower flow rate) was discovered in experiments immediately after the PIV measurement, indicating that aging had occurred (https:// ecn.sandia.gov/diesel-spray-combustion/target-condition/injectorwhereabouts/injector-history/?nam=210679. \#210679). Consequently, earlier measurements of discharge coefficient, area contraction coefficient, and nozzle diameter for injector 201678 [31] do not apply. We therefore refer to this nozzle as "201678-aged." 
Table 1. Boundary conditions of the experiments performed at IFPEN (velocity fields obtained by PIV) and Sandia (mixture fraction fields obtained by Rayleigh scattering)

\begin{tabular}{|l|l|c|c|}
\cline { 3 - 4 } \multicolumn{2}{c|}{} & IFPEN & SANDIA \\
\hline Density & $\mathrm{kg} / \mathrm{m}^{3}$ & $22.8[15.2]$ & $22.8[15.27 .6]$ \\
\hline Temperature & $\mathrm{K}$ & 900 & 900 \\
\hline Injection Pressure & $\mathrm{bar}$ & $1500[1000]$ & $1500[1000]$ \\
\hline Injection Duration & $\mu \mathrm{s}$ & 1500 & 6000 \\
\hline$\% \mathrm{O}_{2}$ & $\% \mathrm{vol}$ & 0 & 0 \\
\hline Fuel & - & n-dodecane & n-dodecane \\
\hline Injector reference & - & 210678 -aged & 210677 \\
\hline Mass flow rate & $\mathrm{g} / \mathrm{s}$ & 2.25 & 2.27 \\
\hline Diameter & $\mu \mathrm{m}$ & 88.6 & 83.7 \\
\hline Momentum & $\mathrm{N}$ & 1.22 & 1.46 \\
\hline Spray Angle & $\circ$ & 20.8 & 21 \\
\hline
\end{tabular}

\section{PIV experimental setup}

The velocity fields are obtained through time-resolved Particle Imaging Velocimetry at $10 \mathrm{kHz}$, whose experimental setup is presented in Figure 2. The beam of a double-pulsed 532nm Nd:YAG (Quantronix Condor, lamp pumped) laser is formed into a laser sheet by the combination of a spherical $(\mathrm{f}=300 \mathrm{~mm})$ and a cylindrical $(\mathrm{f}=-$ $100 \mathrm{~mm}$ ) lens. The focal lengths of the lenses are selected in order to obtain a laser sheet the same width as the entrance window $(80 \mathrm{~mm})$. The laser sheet intercepts the spray axis, in the focal plane of the camera as the injector is horizontally mounted. The two laser pulses are separated by $4 \mu \mathrm{s}$, and the energy of each pulse is approximately $2.3 \mathrm{~mJ}$. The particles used for PIV measurements are porous $\mathrm{SiO} 2$ powder (Seika Corporation, B-6C), with a density $\rho_{\mathrm{p}}=600 \mathrm{~kg} / \mathrm{m} 3$ and an average diameter $d_{p}=2 \mu \mathrm{m}$. They can resist the preburn event necessary to reach high temperatures, and are seeded into the ambient gases during the filling process of the vessel [33].. The ability of these particles to be used as tracer of the flow will be discussed in the "Results" section. A Photron SA1 high-speed camera equipped with a Nikkor $50 \mathrm{~mm} \mathrm{f} / 1.4$ lens is used to collect the Mie scattering on the particles in the direction orthogonal to the laser sheet. The size of images is $704 \times 240$ pixels, corresponding to $75.2 \times 25.6 \mathrm{~mm}$ (with a resolution of $9.4 \mathrm{pixel} / \mathrm{mm}$ ). The images are processed with the LaVision Davis software, using a multi-pass processing with a first pass with a $64 \times 64$ pixels interrogation window and a second pass with $8 \times 8,16 \times 16$ or $32 \times 32$ pixels interrogation window, and $50 \%$ overlap. Vectors corresponding to peak ratio lower than 1.1 are deleted. To achieve statistically meaningful results, the velocity fields are averaged over 10 individual injection events. The convergence of the velocity fields will be evaluated in the Results section The uncertainty of the results, referring to the $95 \%$ confidence interval computed using the Student's t-distribution, will be shown on the results. The peak locking phenomena occurs when particles are smaller than one pixel and is characterized by an over-population of particle displacements taking integer values [34]. It has been estimated in a ROI corresponding to the spray region (see red rectangle on the instantaneous velocity field in Figure 2). The peak lock value computed by the software is lower than 0.1 , which indicates that the peak locking effect is acceptable.
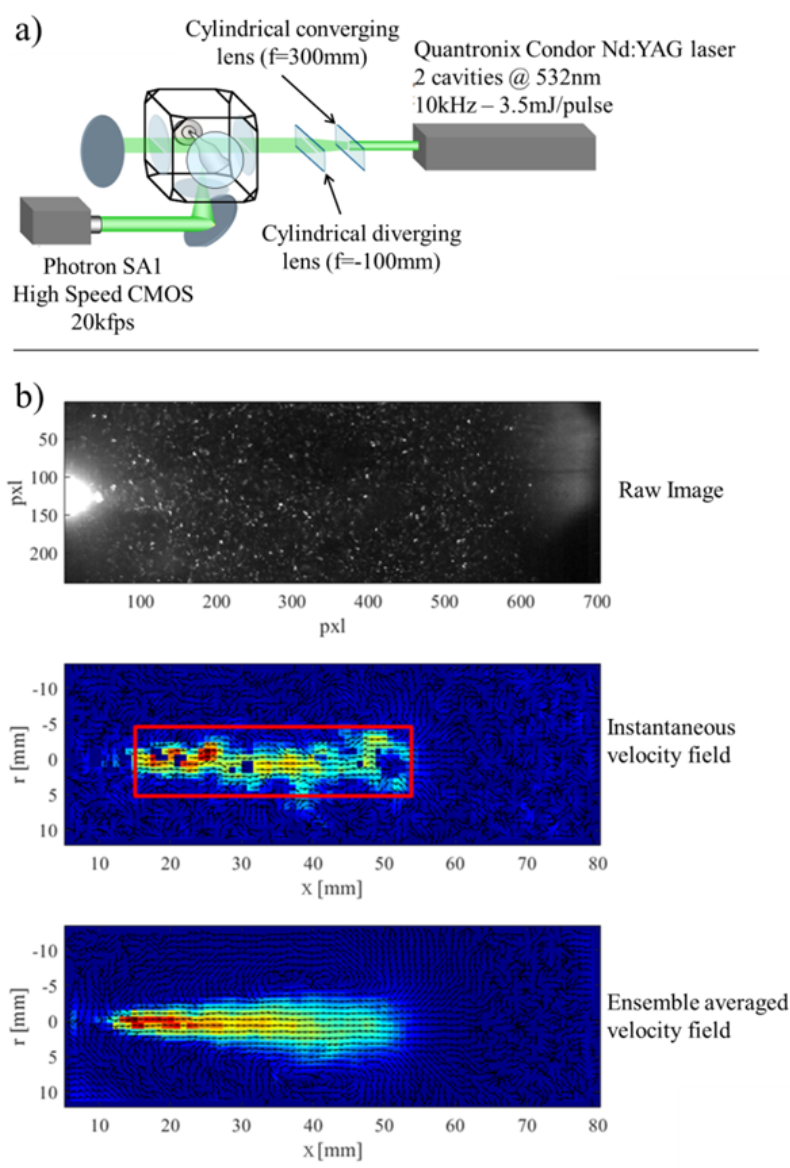

Figure 2 - a) Experimental setup for PIV measurements. b) Example of raw PIV image and related instantaneous velocity field and an ensemble average velocity field. The red rectangle on the instantaneous velocity field indicates the ROI used to estimate peak locking.

\section{Description of the 1D model}

The 1D Diesel spray model has been extensively detailed in the literature $[11,23,29]$. It is based on the main following assumptions:

- the spray is self-similar, with radial shape functions

$$
\begin{aligned}
& u_{x}(x, r)=u_{x, c}(x)\left[1-\left(\frac{r}{R(x)}\right)^{\alpha}\right]^{2} \\
& \xi(x, r)=\xi_{c}(x)\left[1-\left(\frac{r}{R(x)}\right)^{\alpha}\right]^{2}
\end{aligned}
$$

as quasi-Gaussian radial profiles for axial velocity $\mathrm{u}_{\mathrm{x}}$ and fuel volume fraction $\xi$, where $\mathrm{R}(\mathrm{x})$ is the radius of the spray at axial distance $\mathrm{x}, \mathrm{u}_{\mathrm{x}, \mathrm{c}}(\mathrm{x})$ the axial velocity on the spray axis at distance $\mathrm{x}$, and $\xi_{\mathrm{c}}(\mathrm{x})$ the fuel volume fraction on the spray axis at distance $x$. The parameter $\alpha$ defines the shape of the radial profiles. Usually, the value of $\alpha$ has been set to $1.5[11,35]$.

- the vapor angle is constant. The angle is a crucial input parameter of this model that accounts for detailed mixing and entrainment phenomena. Indeed, the exact phenomena occurring at micro-scale level are still not fully understood, 
but they result in a certain spray cone angle. This is the only input that is not directly linked to the boundary conditions and that requires tuning.

- fuel mass flow rate and total momentum are conserved through any cross section of the spray. This means that there is an exchange of momentum between the fuel and the air, and thus that this momentum exchange is the base mechanism of air entrainment.

- With all those assumptions, it is possible to obtain a spatial distribution of axial velocity and fuel volume fraction in the spray. But as mentioned, this requires that the spray angle is known. Following ECN recommendations, the spray angle is derived through vapor penetration measurements [29]

\section{Results}

\section{Validation of the PIV technique}

Several factors can affect the reliability of the velocity measurements performed with the PIV technique. As the injected fuel is liquid, some fuel droplets can be mistaken for particles. But, for the studied conditions, the liquid length is approximately $10 \mathrm{~mm}$, so liquid droplets are unlikely to be present downstream $15 \mathrm{~mm}$. However, among others, the inertia of the particles, the time delay $\Delta t$ between two consecutive laser pulses and the windowing size during PIV cross-correlation analysis have been identified as possible sources of errors. Also, the statistical convergence of the velocity fields on the 10 injection events is assessed. These limitations are discussed in the following paragraphs.

\section{Particles as flow tracers}

The Stokes number $S_{k}$ is usually used as a criterion to assess whether or not particles are relevant tracers of a given flow. $S_{k}$ is defined as the ratio of the characteristic time of the particles $\tau_{p}$ to that of the flow $\tau_{f}$, or in other words as the ratio of the acceleration of the particle to that of the surrounding fluid. The characteristic time of the particle $\tau_{p}$ can be estimated through the equation of the motion of a spherical particle into an unsteady fluid. This equation has first been given by Basset [36] and later discussed by Melling [37] and Mei [38] for PIV applications. In the case of a high density ratio between the seeding particles and the ambient flow, as shown in [37], the equation simplifies to:

$$
\frac{d u_{p}}{d t}=-\frac{1}{\tau_{p}}\left(u_{p}-u_{f}\right)
$$

where $u_{p}[\mathrm{~m} / \mathrm{s}]$ is the particle velocity, $u_{f}[\mathrm{~m} / \mathrm{s}]$ is the flow velocity. $\tau_{\mathrm{p}}$ is given by:

$\tau_{p}=\frac{4}{3} \frac{1}{C_{d} R e_{p}} \frac{\rho_{p} d_{p}^{2}}{\mu}$, with $R e_{p}=\frac{\rho_{f} \cdot\left|u_{p}-u_{f}\right| \cdot d_{p}}{\mu}$

where $\mathrm{C}_{\mathrm{d}}[-]$ is the drag coefficient, $\operatorname{Re}_{\mathrm{p}}[-]$ the particle Reynolds number, $\mu[$ Pa.s $]$ the fluid's dynamic viscosity, $\rho_{\mathrm{p}}[\mathrm{kg} / \mathrm{m} 3]$ the particle's density and $d_{p}[\mathrm{~m}]$ its diameter, and $\rho_{\mathrm{f}}[\mathrm{kg} / \mathrm{m} 3]$ the fluid's density.

For $\mathrm{Re}_{\mathrm{p}}$ lower than approx. 1, the Stokes' drag law applies and $\mathrm{C}_{\mathrm{d}}$ can be estimated by $C_{d}=24 / R_{e}$.

Page 4 of 12
This is a conservative assumption since it underestimates the real value of $C_{d}$ when $R_{p}>1$. This ultimately leads to the following formula for $\tau_{\mathrm{p}}$ :

$$
\tau_{p}=\frac{\rho_{p} d_{p}^{2}}{18 \mu}
$$

The ambient gases are a mixture of $\mathrm{N}_{2}, \mathrm{CO}_{2}$ and $\mathrm{H}_{2} \mathrm{O}$, having a dynamic viscosity $\mu \approx 4 \cdot 10^{-5} \mathrm{~Pa}$.s at $800 \mathrm{~K}$. This leads to $\tau_{\mathrm{p}}=3 \mu \mathrm{s}$.

Concerning the flow, it can be decomposed into its average and turbulent components. Each of them has a different characteristic time $\tau_{\mathrm{f}}$. However, in this study, since the only the average velocity fields are considered, the characteristic time of interest is the one corresponding to the average flow. Considering the average flow, its characteristic time can be inferred from the particulate derivative of the flow, considering only the axial component $u_{x}$ of the velocity (along the $\mathrm{x}$-axis of the spray) :

$\overrightarrow{u_{f}}=u_{x} \cdot \vec{x}$ gives $\frac{d u_{x}}{d t}=\frac{\partial u_{x}}{\partial t}+u_{x} \frac{d u_{x}}{d x}$.

If we consider the steady-state regime of the flow, we have:

$\frac{\partial u_{x}}{\partial t}=0$ and then $\frac{d u_{x}}{d t}=u_{x} \frac{d u_{x}}{d x}=u_{x} \cdot \frac{1}{\tau_{f}}$

Using the 1D spray model to derive the velocity field, its derivative along the $\mathrm{x}$-axis can be computed and we can therefore obtain a 2D map of $\tau_{f}$, and then a 2D map of the Stokes number. The logarithm in base 10 of this Stokes number is plotted in Figure 3. It appears that $\mathrm{S}_{\mathrm{k}}<1$ on the whole 1D spray, and is lower than 0.01 for axial distances greater than $20 \mathrm{~mm}$. This indicates that the particles are relevant tracers for the average flow in the spray.

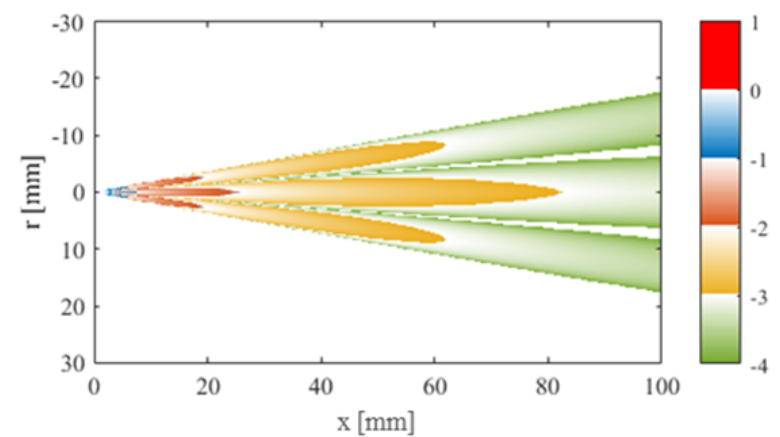

Figure 3 - 2D map of $\log 10\left(S_{\mathrm{k}}\right)$ based on $\tau_{\mathrm{p}}$ estimated from the particles characteristics and $\tau_{\mathrm{f}}$, extracted from the 1D-spray model based flow acceleration

\section{Convergence of the velocity fields}

As explained in the description of the experimental setup, velocity fields are ensemble averaged on 10 injections. The obtained results are presented in Figure 4, for a delay of $4 \mu \mathrm{s}$, an interrogation window of $16 \times 16$ pixels and a timing corresponding to $1.6 \mathrm{~ms}$ after SOI. The convergence of the resulting ensemble averaged velocity fields must be assessed. This is done by looking at the convergence of the velocities at 4 positions arbitrarily selected on the spray axis, at $20 \mathrm{~mm}, 30 \mathrm{~mm}, 40 \mathrm{~mm}$ and $50 \mathrm{~mm}$ from the orifice of the injector, 
represented by gray cricles. It appears that the convergence of the velocity fields is not satisfying, since the confidence intervals are between $10 \%$ and $20 \%$ of the corresponding average velocity. This value is considered too high to allow a proper comparison between the measured velocity fields and the ones estimated with the 1D spray model.
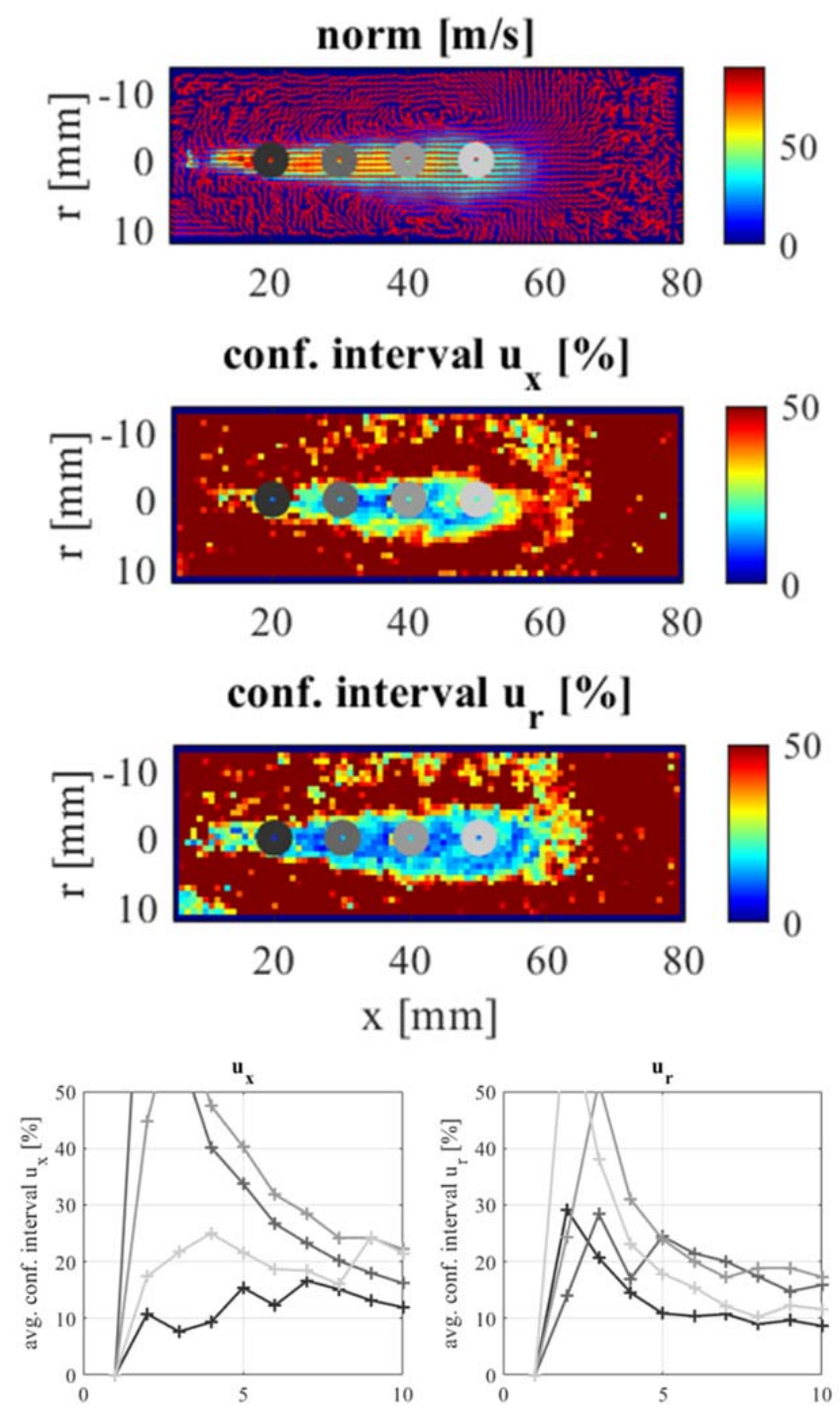

Figure 4 - Top three images: evaluation of the statistical convergence of the ensemble averaged velocity fields, for a delay of $4 \mu \mathrm{s}$, an interrogation window of $16 \times 16$ pixels and a timing corresponding to $1.6 \mathrm{~ms}$ after SOI. Bottom two images: evolution of the confidence interval normalized by the average velocity, for the locations corresponding to the gray circles.

To overcome this limitation, and since for this study only the steadystate average velocity fields are of interest, reconstructed steady-state velocity fields can be computed. At each axial location, the radial profiles of the axial velocity $u_{x}$ from the ensemble average velocity field and at all the timings are considered. For velocity fields spanning from SOI to EOI $+2 \mathrm{~ms}$, at $10 \mathrm{kHz}$, this gives 36 radial profiles at each axial location. For $x=39.7 \mathrm{~mm}$, these profiles are plotted on Figure 5. All the profiles whose maximum value is greater Page 5 of 12 than a certain percentage of the highest value are considered to correspond to steady-state timings. This percentage has been arbitrarily set to $80 \%$. For the case presented in Figure 5, the velocities are in steady-state between $0.9 \mathrm{~ms}$ and $1.8 \mathrm{~ms}$ after SOI. During this time range, no systematic trend on the maximum value of the velocity is observed, which confirms that the steady-state has been truly identified. This analysis is performed for all the axial distances, allowing to identify the steady-state timings at each axial location. Then, these steady-state timings are used to select the steady-state profiles on the 10 injections events. Thus, at each axial location, instead of having only 10 profiles to compute the ensemble average, there are 10 multiplied by the number of steady-state timings, which leads to a better statistical convergence. These profiles are plotted in Figure 5, bottom, for the case $x=39.7 \mathrm{~mm}$. It appears that, although the standard deviation $\sigma$ is quite high, the uncertainty $u$ is about $5 \%$ of the mean value since it is computed on 100 profiles.
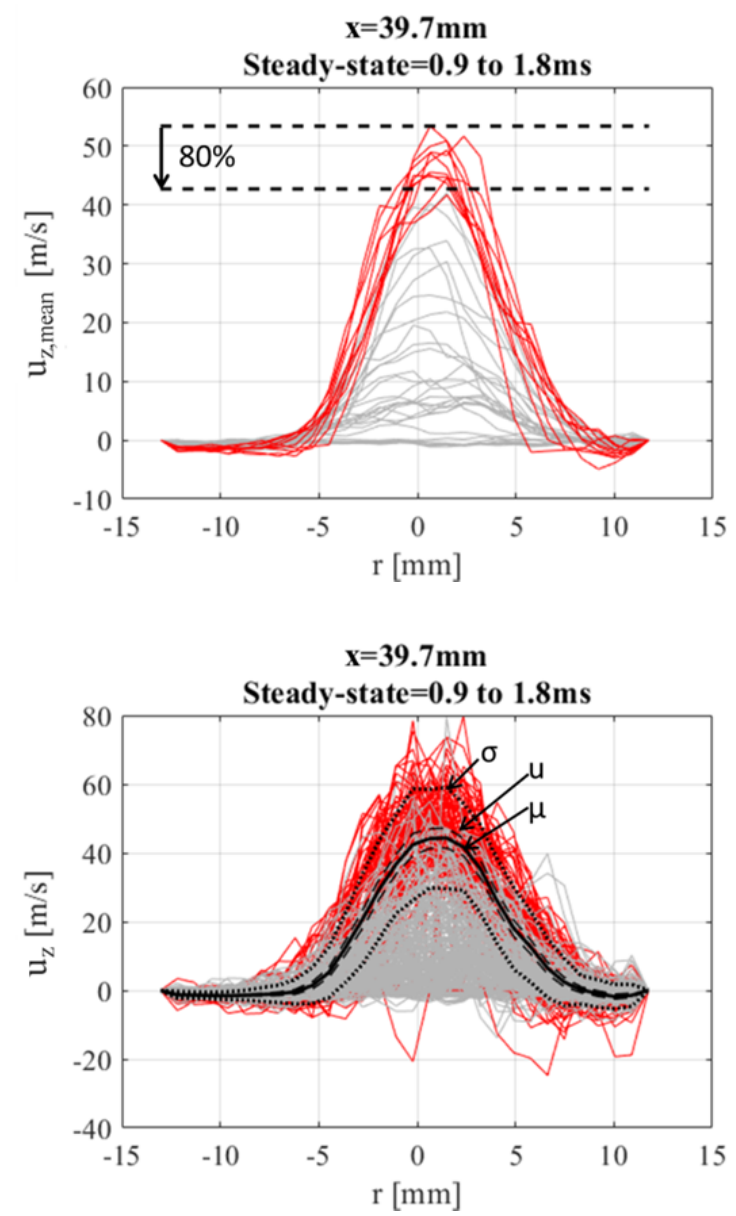

Figure 5 - Top: ensemble averaged radial profiles of the axial velocity, for all the timings between SOI and EOI $+2 \mathrm{~ms}$. Red profiles are considered to be representative of the steady-state, gray ones are considered transient. Bottom: Same as the top figure, for all the instantaneous radial profiles. The mean $\mu$, standard-deviation $\sigma$, and uncertainty $u$ are plotted respectively in plain, dotted and dashed black lines.

Using this methodology, the convergence of the reconstructed steadystate velocity fields is presented in Figure 6. Figure 6 is similar to Figure 4, but for the reconstructed steady-state velocity field. In this 
case, it appears that the confidence intervals are about $5 \%$ of the average velocity, which is much lower than the value plotted in Figure 4. In the following, all the velocity profiles that are discussed are extracted from the reconstructed steady-state velocity fields.
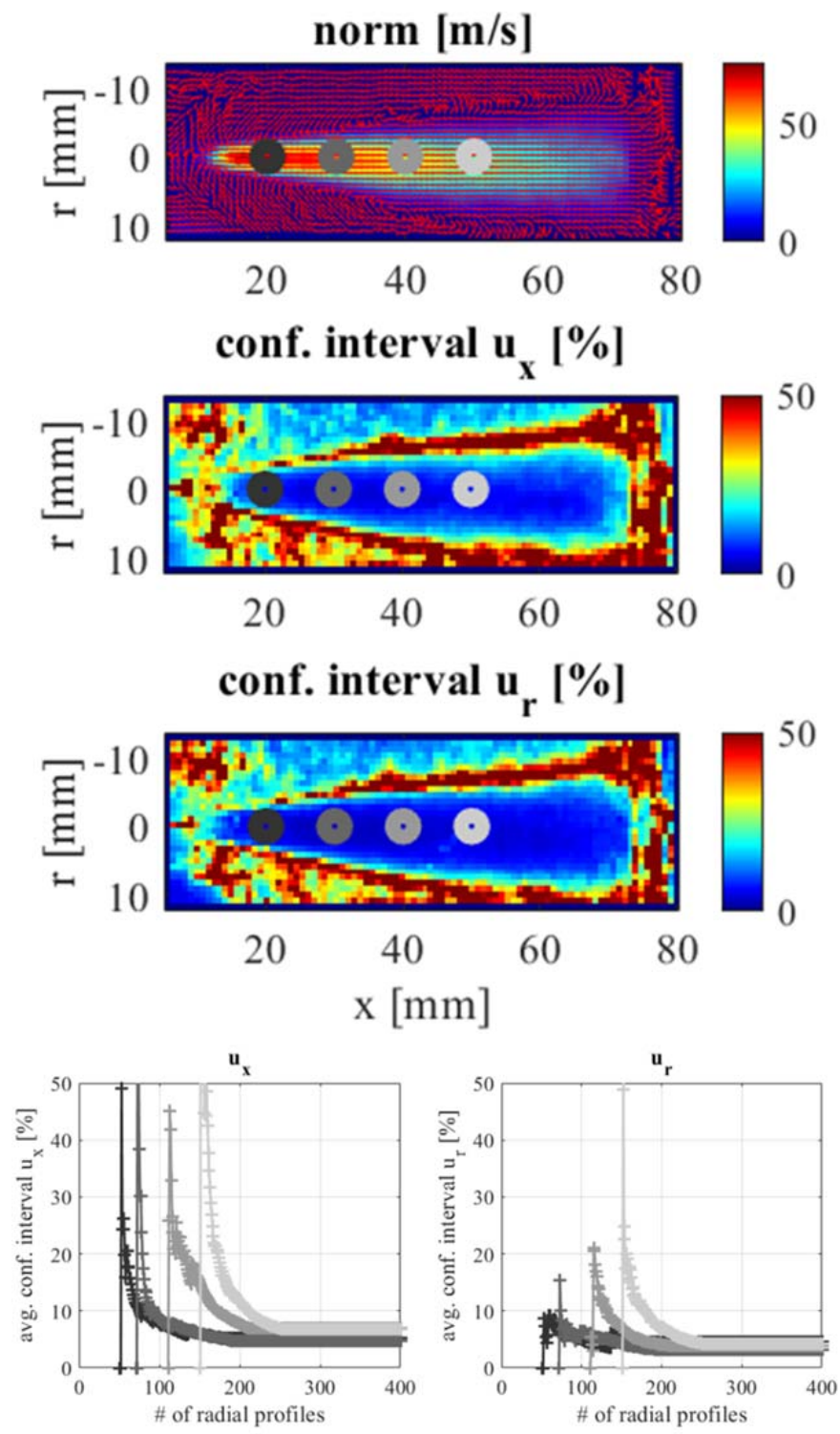

Figure 6 - Top three images: Evaluation of the statistical convergence of the instantaneous velocity fields, for a delay of $4 \mu \mathrm{s}$ and an interrogation window of $16 \times 16$ pixels after SOI. Bottom two images: evolution of the confidence interval normalized by the average velocity at the locations indicated by the grey cross of the left hand side images.

\section{Delay $(\Delta t)$ between laser pulses}

Another possible source of error is the delay $\Delta \mathrm{t}$ between two consecutive laser pulses. If this delay is too large, the movement of the particles between two consecutive laser pulses is too large, and the PIV correlation algorithm fails to determine the correct displacement. On the opposite, if it is too short, the displacement is

Page 6 of 12 too small to be accurately determined compared to the image resolution. The former case is an issue when considering the high velocities near the nozzle tip. In order to assess the impact of this delay, a variation of its value has been performed, in the non-reacting Spray A conditions. In addition to the standard delay of $4 \mu \mathrm{s}$, delays of $10 \mu \mathrm{s}$ and $20 \mu \mathrm{s}$ have been tested. Figure 7 shows the centerline axial velocities corresponding to these different delays, for an interrogation window size of $16 \times 16$ pixels.
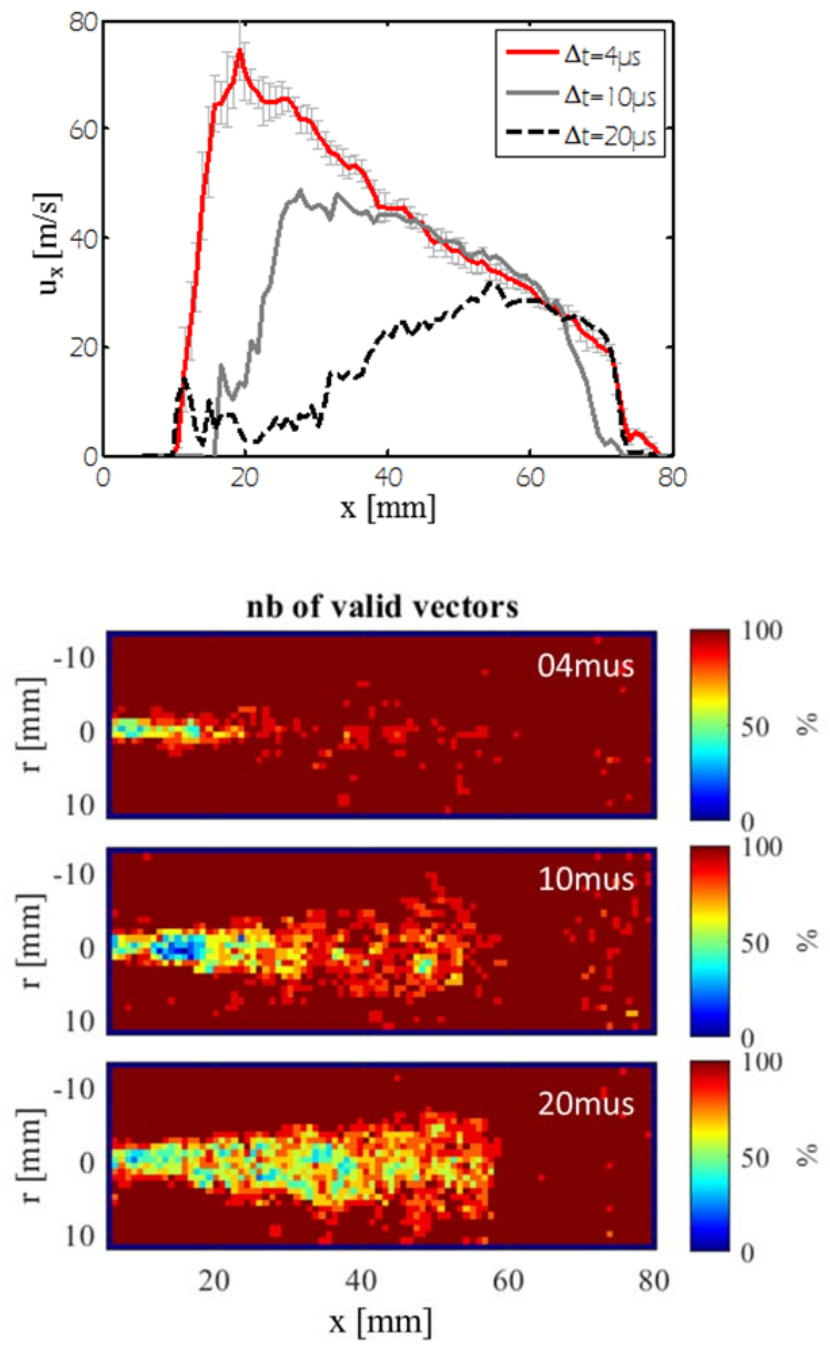

Figure 7 - Influence of the delay $\Delta t$ between 2 laser pulses on the measured axial velocity for an interrogation window size of $16 \times 16$ pixels (top), and on the validity of the computed vectors (bottom three images)

It appears that, in the very far field $(x>50 \mathrm{~mm})$, the axial velocities are similar for the three values of $\Delta \mathrm{t}$. This tends to prove that, in that region, the measurements are not dependent upon the value of the delay between the laser pulses. However, for shorter distances, Figure 7 shows that higher $\Delta \mathrm{t}$ are not able to resolve high velocities. A $\Delta \mathrm{t}$ of $20 \mu$ s permits measurement of velocities lower than $30 \mathrm{~m} / \mathrm{s}$. For higher velocities $(\mathrm{x}<50 \mathrm{~mm})$, the measurements are diverging from the 2 other values of $\Delta \mathrm{t}$. The same can be observed for $\Delta \mathrm{t}=10 \mu \mathrm{s}$ : below $40 \mathrm{~mm}$ (i.e. velocities higher than $40 \mathrm{~m} / \mathrm{s}$ ), the measurements are not relevant. For the delay used in this study $(\Delta \mathrm{t}=4 \mu \mathrm{s})$, there is 
also a maximum value for the velocities that can be resolved. And it is probable that the unphysical drop in velocity observed below $20 \mathrm{~mm}$ is caused by the existence of this limitation, as the velocities tend to be higher near the nozzle tip. This can be confirmed by the statistics on the validity of the computed vectors, shown on the 3 bottom images in Figure 7. As explained in the description of the PIV technique, vectors whose peak ratio is lower than 1.1 are deleted. Therefore, for each location, the numbers of valid vectors in the ensemble average can be counted. This is shown in Figure 7. It appears that when the delay increases, the number of valid vectors decreases. The most favorable case is thus obtained with a delay of $4 \mu \mathrm{s}$. But even in this case, the number of valid vectors drops for $\mathrm{x}<20 \mathrm{~mm}$ on the spray axis, which confirms that the velocities computed in this region are not reliable. From a theoretical point of view, to allow a correct detection, the time interval $\Delta t$ must respect the following criteria [39]:

$$
\Delta t<0.25 . d_{I} /|u|
$$

where $\mathrm{d}_{\mathrm{I}}$ is the size of the interrogation window. In our case, knowing $\Delta t$ and $\mathrm{d}_{\mathrm{I}}$, we can compute the theoretical maximum value of the velocity that can be computed. This gives $106 \mathrm{~m} / \mathrm{s}, 45 \mathrm{~m} / \mathrm{s}$ and $30 \mathrm{~m} / \mathrm{s}$ respectively for $\Delta t 4 \mu \mathrm{s}, 10 \mu \mathrm{s}$ and $20 \mu \mathrm{s}$. This is in agreement with the empirical values we have measured $(70 \mathrm{~m} / \mathrm{s}, 40 \mathrm{~m} / \mathrm{s}$ and $30 \mathrm{~m} / \mathrm{s})$. This means that the limitations in velocity measurement observed when varying $\Delta t$ are governed by the respect of the criteria in Eq. 6. Only for the lower value of $\Delta t=4 \mu s$ the measured maximum velocity $(70 \mathrm{~m} / \mathrm{s})$ is lower thant the expexted one $(106 \mathrm{~m} / \mathrm{s})$. However, in this case, the radial velocity gradients are higher, and can affect the measurement. This will be discussed below. Thus, based on what is seen on Figure 7, velocity measurements will not be considered to be reliable for distances lower than $20 \mathrm{~mm}$.

\section{Window size for cross-correlation processing}

The size of the interrogation window defined for the processing of the PIV results can also have an impact on the measurements. Figure 8 shows the axial velocities obtained with 3 different values of interrogation window. It appears that, downstream of $40 \mathrm{~mm}$, all the profiles are similar, therefore we can conclude that the velocities are not significantly affected by the size of the window in this region of the jet. However, below $40 \mathrm{~mm}$, some discrepancies appear between the $32 \times 32$ results and the other 2 . Below $30 \mathrm{~mm}$, the same deviation appears between the $8 \times 8$ and $16 \times 16$ results.

The differences in the resulting velocity fields processed with different windows size could be caused by the velocity gradients existing inside the interrogation windows. This has been studied by Keane and Adrian [40] and also discussed by Westerweel [41]. They have shown that the velocity gradients inside an interrogation window can be neglected when the following condition is satisfied:

$$
|a| \ll d_{p} \text {, with } a \equiv M \Delta \mathbf{u} \Delta t
$$

where $d_{p}$ is the particle diameter and a is its local displacement, $M$ is the image magnification, $\Delta \mathrm{t}$ is the delay between two laser pulses and $\Delta u$ the local variation of the velocity. In the case of the Diesel spray, the gradients of interest are the radial ones since they are higher than the axial ones. Using the 1d spray model, the radial gradients of axial velocity can be computed for square interrogation windows of 8,16 and 32 pixels, at each axial location of the spray. Then the criteria defined in Eq. 8 can be estimated with $\mathrm{M}=9.4 \mathrm{pxl} / \mathrm{mm}$ and $\Delta \mathrm{t}=4 \mu \mathrm{s}$, and $d_{p}=1$ pxl. The results are presented in Figure 9, showing that for

Page 7 of 12 an interrogation window of $8 \times 8$ pixels (resp. $16 \times 16$ and $32 \times 32$ ), the criterion is met when $x>20 \mathrm{~mm}$ (resp. $x>30 \mathrm{~mm}$ and $x>40 \mathrm{~mm}$ ). Interestingly, the axial locations where the criteria are true are similar to the ones where the interrogation window size has no effect on velocity profile, as described in Figure 8.

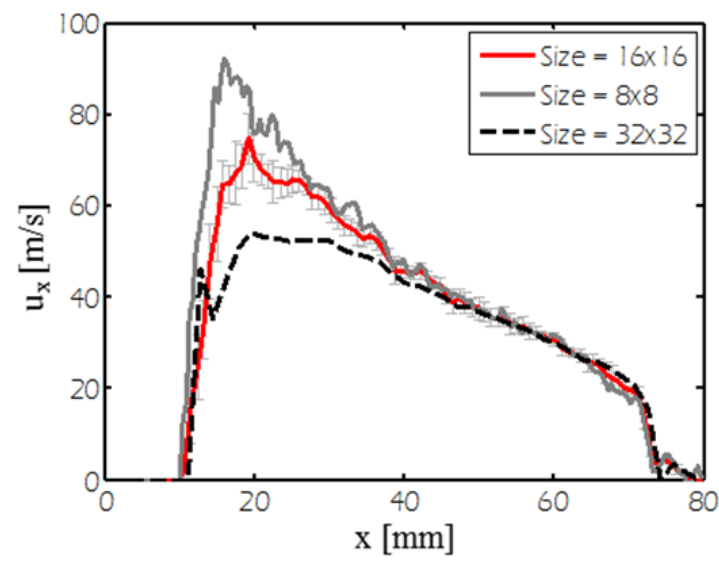

Figure 8 - Influence of window size on the measured centerline axial velocity

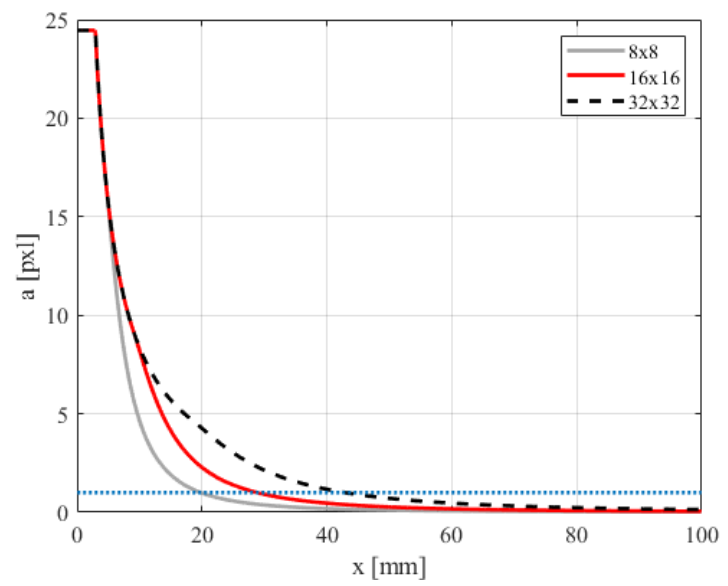

Figure 9 - Axial evolution of $|\mathbf{a}|$ for different sizes of interrogation window, and comparison with $d_{p}$ (blue dotted line)

However, even if an $8 \times 8$ window size captures a wider velocity range, the oscillations visible for the corresponding curve also shows that this lower window size also generates a lower measurement precision. As a compromise, in the present work the processing has been performed with 16x16 pixels interrogation windows. Figure 9, shows that at distances from the injector below $30 \mathrm{~mm}$ the measurement are probably less reliable.

This analysis of the limits of the velocity measurements shows that a good accuracy is difficult to obtain for measurements at distances shorter than $30 \mathrm{~mm}$ from the nozzle because of the inertia of the particles, the effect of time delay between laser pulses and/or of the interrogation window size. Therefore, in the following sections, only velocities downstream of $30 \mathrm{~mm}$ will be considered. Besides, the inertia of the particles can also affect the velocities in the far field $(x>30 \mathrm{~mm})$, so the results must be carefully analyzed. As discussed in 
the introduction of this paper, these experimental results will be analyzed to validate the hypothesis of the 1D spray model, and to assess the consistency of the velocity and mixture fraction fields database.

\section{Performances of the 1D spray model}

Figure 10 and Figure 11 show the comparison between experimental and modeled data for each condition, for the axial component of the velocity and the mixture fraction, both on the spray axis. The solid lines are for the experimental results, the dashed lines are for the 1D spray model. As discussed earlier, the velocity fields are not reliable below $30 \mathrm{~mm}$, which is why the axial plots for velocity start at $30 \mathrm{~mm}$, compared to $20 \mathrm{~mm}$ for the mixture fraction. Each color corresponds to one type of boundary conditions.
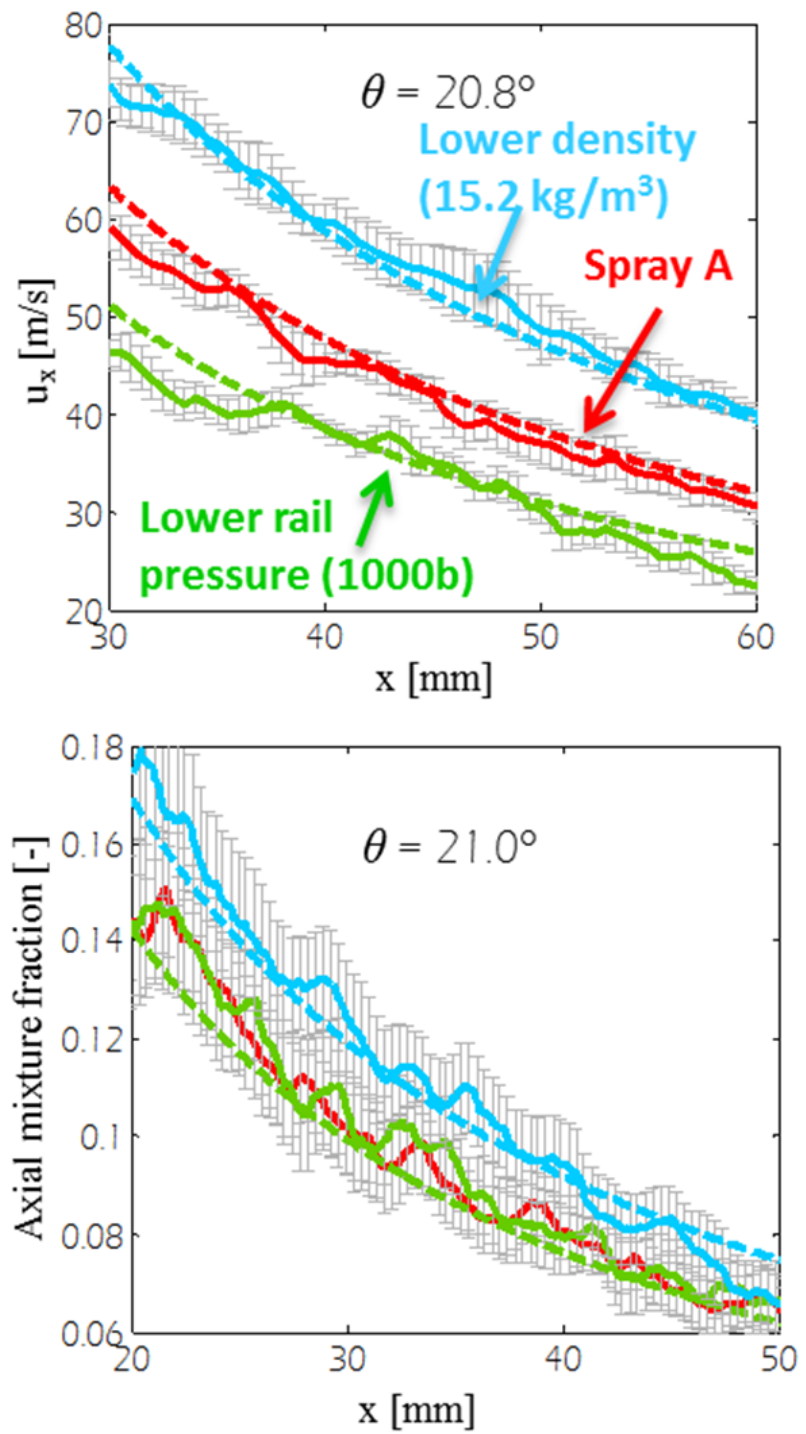

Figure 10 - Velocity (top) and mixture fraction (bottom) axial profiles for different boundary conditions. Solid lines represent the experimental results, dotted lines the model. The grey error bars represent the $95 \%$ confidence interval uncertainties

Page 8 of 12
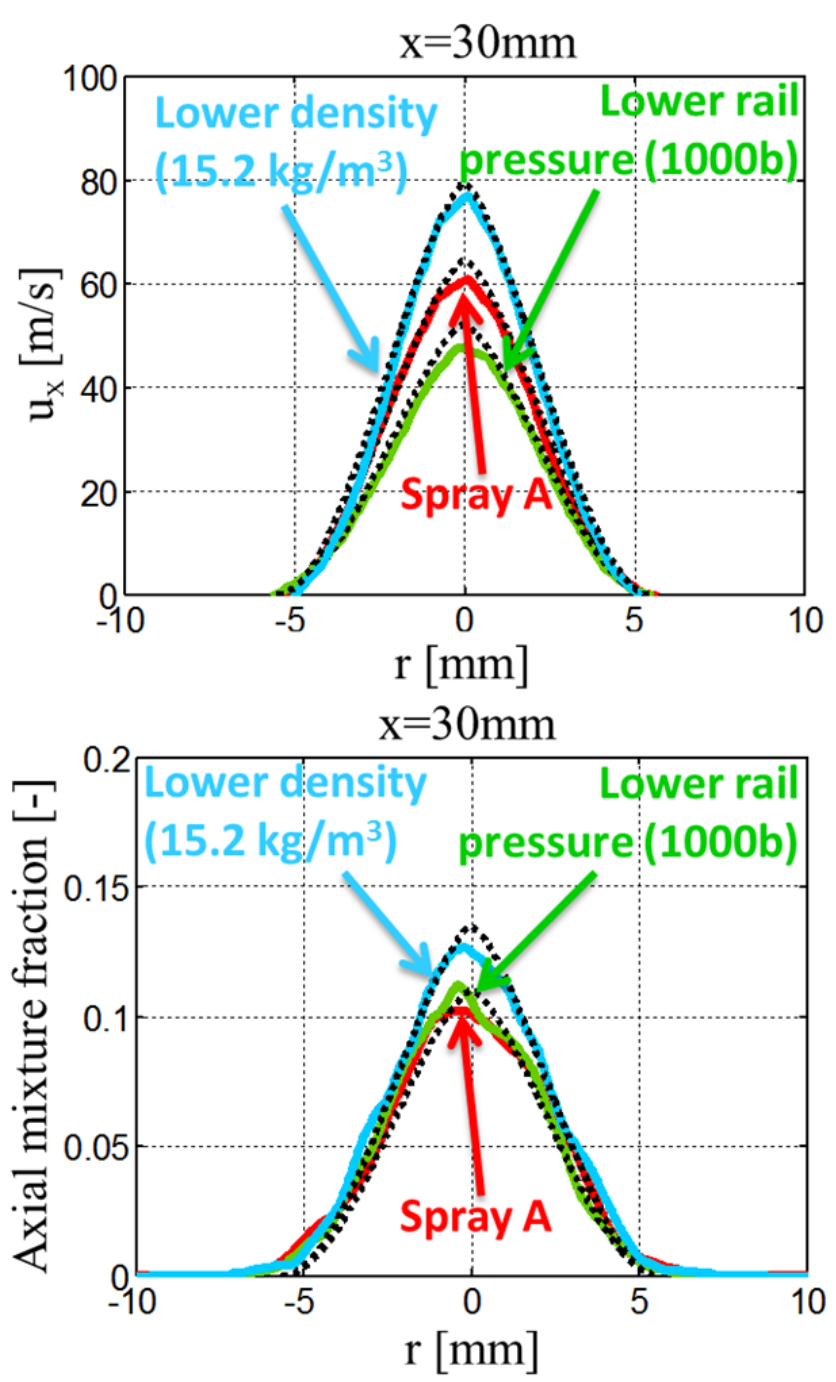

Figure 11 - Velocity (top) and mixture fraction (bottom) radial profiles for different boundary conditions at $x=30 \mathrm{~mm}$. Solid lines represent the experimental results, black dotted lines the model.

Figure 10 and Figure 11 show good agreement between experiment and model for all the cases considered, within the uncertainty of the measurement, suggesting that the $1 \mathrm{D}$ spray model responds appropriately to the variations in the boundary conditions. Therefore, this result further validates the 1D model and its founding hypotheses. Since the model is based on the solving of mass momentum and mass conservation equations, it shows that the mixing process and flow dynamics of the spray are driven by the mass flow rate and mass momentum exchanges.

Besides, these figures show that the effects of boundary conditions variations on the velocity and mixture fraction fields are consistent with previous results from the literature [42-44]. A decrease of the injection pressure does not affect the mixture fraction field in the spray while the axial velocity is affected. This result is explained by the fact that although the mass momentum decreases, it has no effect on the mixture fraction field because the air entrainment is proportional to the injected fuel mass flow rate. A decrease of 
ambient density affects both the mixture fraction and the velocity fields, which are increasing.

These results also allow the analysis of the ability of the ceramic particles used in the PIV technique to follow the actual flow. Indeed, it has been shown that:

- The experimental axial velocity profiles are very similar to the modelled ones, and that the model captures very well the behaviour of the real spray;

- The normalized evolution of axial mixture fraction and velocity profiles are also similar. Also, no major deviation due to particle inertia is observed.

These two observations tend to prove that the particles used in this study to measure the velocities in the spray are good markers of the flow, i.e. that they have a low enough inertia.

\section{Consistency between PIV and Rayleigh measurements}

In the previous section, velocity and mixture fraction fields (carried out with different ECN injectors) were compared to 1D model simulation results adapted to each injector characteristics. The velocity field was compared to model results using input momentum and mass flow rates and spray angle of injector 210678-aged, while mixture fraction fields were compared to model results using injector 210677 inputs. All these characteristics are listed in Table 1. The results presented in Figure 10 show that the results fall within the measurement uncertainty. But this analysis does not give a clue whether or not the velocity field obtained with injector 210678-aged is consistent with the mixture fraction field obtained with injector 210677. In other words, if the mixture fraction field had been measured on injector 210678-aged, would we have obtained the same results as obtained with injector 210677 ? This question is the core of the ECN philosophy. Indeed, the aim of the ECN is to build a unique and complete database, and this effort relies on the use of nominally identical injectors. Previous work has shown that in practice slight differences exist between these injectors [45]. It is therefore interesting to evaluate the effect of these differences on the consistency between the datasets. This question can be addressed by the use of the 1D spray model, which has been shown in the previous section to provide an accurate estimation of the behaviour of the real spray. Using this model, it is possible to estimate the mixture fraction field corresponding to injector 210678-aged, for which only the velocity field has been measured. And reciprocally, the velocity field of injector 210677 can also be estimated with the 1D spray model.

Figure 12 and Figure 13 compare experimental velocity (in gray) and mixture fraction axial profiles obtained with 1D model simulations corresponding to both injectors (colored lines, solid lines for injector 210677 , dashed lines for injector 210678-aged). Regarding the mixture fraction fields, the modelling results for injector 210678 aged are slightly higher than for injector 210677. However, the results (dashed line) are also within the uncertainty of the measurements, but the agreement is better for injector 210677 , the one that was actually used for these mixture fraction measurements. Concerning the velocity fields, injector 210677 shows higher axial velocities than injector 210678-aged, in line with its higher momentum rating (Table 1). But once again, the actual injector used for the velocity study was 210678 -aged. This therefore shows that although the ECN injectors are nominally identical, in practice existing differences have to be considered when comparing datasets obtained from different injectors. Of course, ideally injectors could be made to tighter specification, or aging could be controlled such that their performance would not change throughout time. These differences between nominally identical injectors have already been observed in $[32,45]$ using standard optical diagnostics for the characterization of spray penetration and combustion, but have not been demonstrated for velocity and mixture fraction requiring more complex diagnostics. Thus, the experimental database for velocity and mixture fraction fields, even if they are close, are not completely consistent with one another. The difference in the injected momentum between injectors 210677 and 210678-aged leads to significant differences in mixture fraction and velocity fields. But the 1D spray model, once calibrated, can be used to bring consistency between different experimental databases.

\section{Conclusion}

The process of Diesel spray mixture formation was investigated within the ECN framework. High-speed Particle Image Velocimetry was used to measure the velocity field inside the jet. The PIV measurements were carried out at Spray A target conditions with injector 210678-aged, enabling direct comparisons with mixture fraction measurements previously performed under the same conditions with injector 210677. A 1D spray model, based on fundamental hypothesis on the dominant processes of spray formation, was used to evaluate the latter hypothesis and to compare quantitatively the consistency between the two databases. The spray angle is fitted to match the measured vapor penetration. With this input vapor angle, the $1 \mathrm{D}$ spray model is able to predict quantitatively the main spray characteristics (average mixture fraction and velocity fields) within the measurement uncertainties and for a wide range of parametric variations. At last, the 1D spray model has been used to show that the differences between injector 210677 and 210678-aged will induce slightly different velocity and mixture fraction fields. However, a consistent database can be built using advanced diagnostics performed by different institutions when the boundary conditions are well known like in the ECN Spray A framework, and when the 1D model is used to assess the difference between injectors characteristics. In a general perspective, these results show that the global processes of mixture formation are well understood, but that in order to enable fully predictive simulations, the key is the understanding of the physical processes that determine the angle of the spray. This will only be achieved when the relation between internal nozzle flow and near field spray structure is well understood. This is a major challenge that has been identified within the ECN collaboration. Also improvements of the measurement accuracy in the high velocity regions close to the liquid spray tip should be considered.

Page 9 of 12 


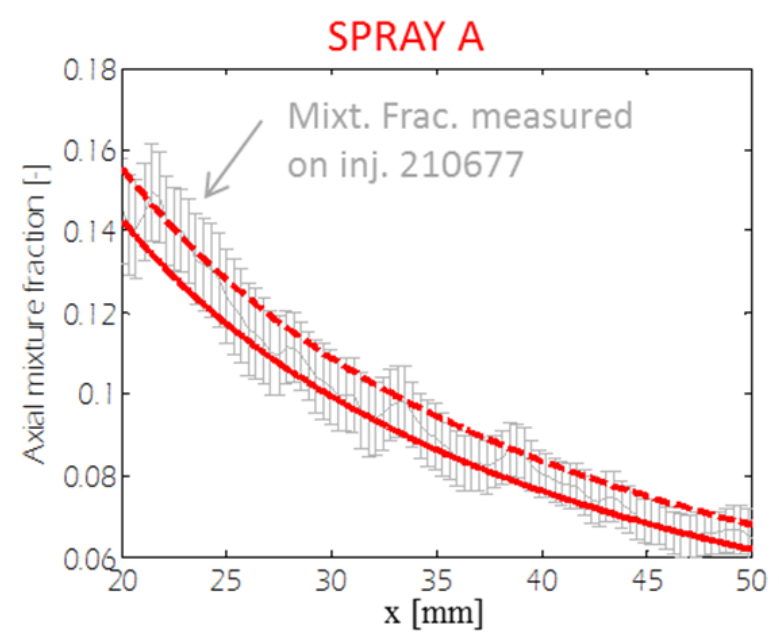

LOWER RAIL PRESSURE (1000 BAR)
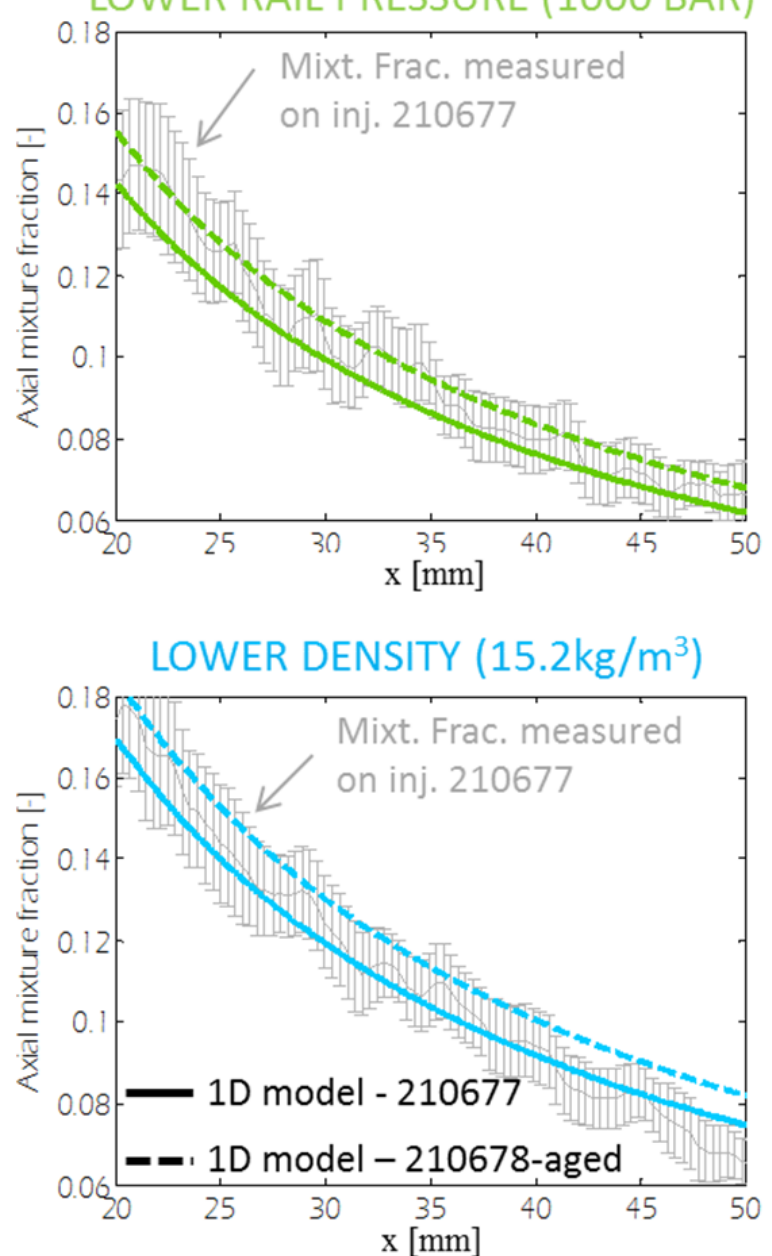

Figure 12 - Comparison of mixture fractions experimental results (in gray) with modeled ones. Solid lines are the estimations from the 1D spray model for injector 210677; dashed lines for injector 210678-aged.

Page 10 of 12
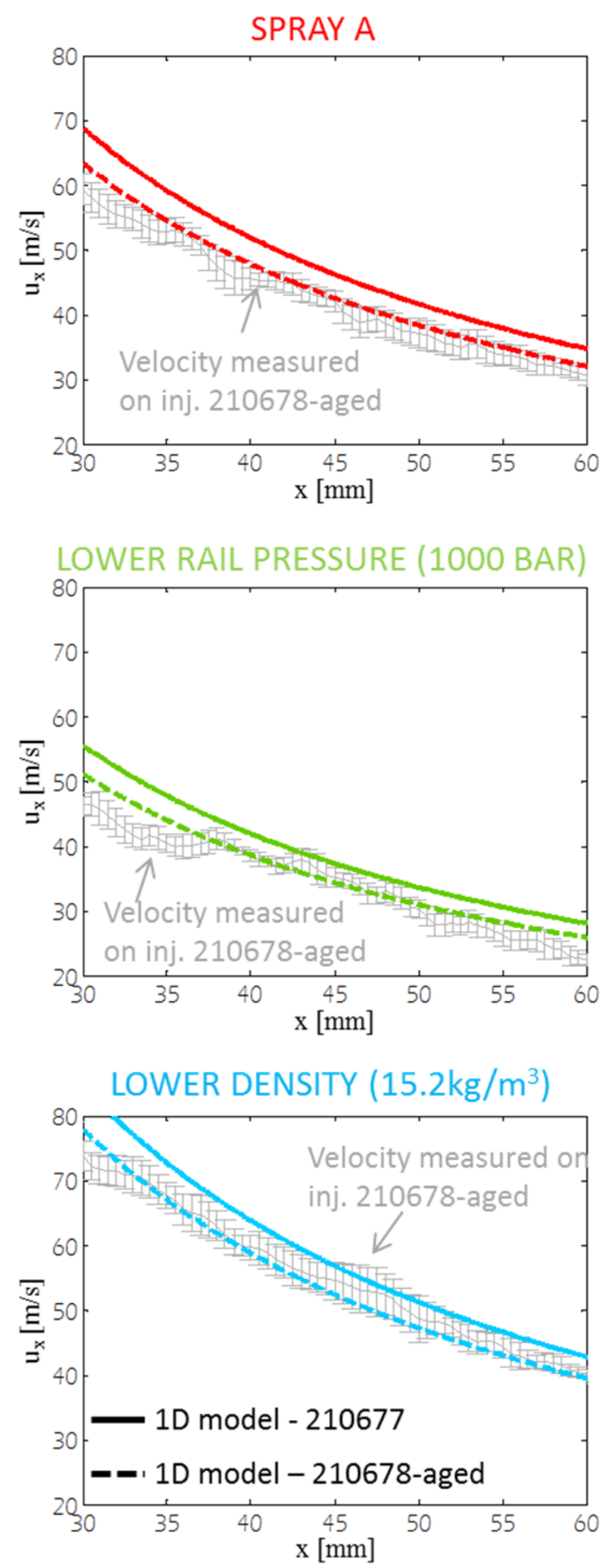

Figure 13 - Comparison of velocity experimental results (in gray) with modeled ones. Solid lines are the estimations from the 1D spray model for injector 210677; dashed lines for injector 210678-aged. 


\section{References}

[1] Siebers, D.L. and Higgins, B., "Flame Lift-Off on DirectInjection Diesel Sprays Under Quiescent Conditions," $S A E$ Technical Paper 2001-01-0530, 2001.

[2] Pickett, L.M. and Siebers, D.L., "An Investigation of Diesel Soot Formation Processes Using Micro-Orifices," Proceedings of the Combustion Institute 29:655-662, 2002.

[3] Siebers, D.L., Higgins, B.S., and Pickett, L.M., "Flame Lift-Off on Direct-Injection Diesel Fuel Jets: Oxygen Concentration Effects," SAE Technical Paper 2002-01-0890, 2002.

[4] Polonowski, C.J., Mueller, C.J., Gehrke, C.R., Bazyn, T. et al., "An Experimental Investigation of Low-Soot and Soot-Free Combustion Strategies in a Heavy-Duty, Single-Cylinder, Direct-Injection, Optical Diesel Engine," SAE Technical Paper 2011-01-1812, 2011.

[5] Bergstrand, P. and Denbratt, I., "The Effects of Leaner Charge and Swirl on Diesel Combustion," SAE Technical Paper 200201-1633, 2002.

[6] Aronsson, U., Chartier, C., Andersson, Ö., Egnell, R. et al., "Analysis of the Correlation Between Engine-Out Particulates and Local AFR in the Lift-Off Region of a Heavy Duty Diesel Engine Using Raman Spectroscopy," SAE Technical Paper 2009-01-1357, 2009.

[7] Upatnieks, A. and Mueller, C.J., "Investigation of the Relationship Between DI Diesel Combustion Processes and Engine-Out Soot Using an Oxygenated Fuel," SAE Technical Paper 2004-01-1400, 2004.

[8] Donkerbroek, A.J., Boot, M.D., Luijten, C C M, Dam, N.J. et al., "Flame lift-off length and soot production of oxygenated fuels in relation with ignition delay in a DI heavy-duty diesel engine," Combustion and Flame 158(3):525-538, 2011.

[9] Bergstrand, P. and Denbratt, I., "Diesel Combustion with Reduced Nozzle Orifice Diameter," SAE Technical Paper 200101-2010, 2001

[10] Musculus, Mark P B, Lachaux, T., Pickett, L.M., and Idicheria, C.a., "End-of-Injection Over-Mixing and Unburned Hydrocarbon Emissions in Low-Temperature-Combustion Diesel Engines," SAE Technical Paper 2007-01-0907, 2007.

[11] Musculus, Mark P B and Kattke, K., "Entrainment Waves in Diesel Jets," SAE Technical Paper 2009-01-1355, 2009.

[12] Eagle, W.E., Musculus, Mark P B, Malbec, L.-M., and Bruneaux, G., "Measuring transient entrainment rates of a confined vaporizing diesel jet," ILASS Americas, 26th Annual Conference on Liquid Atomization and Spray Systems, 2014.

[13] Malbec, L.-M., Eagle, W.E., Musculus, Mark P B, and Schihl, P., "Influence of injection duration and ambient temperature on the ignition delay in a $2.34 \mathrm{~L}$ optical diesel engine," $S A E$ Technical Paper 2015-01-1830, 2015.

[14] Dahm, W J A and Dimotakis, P.E., "Measurements of Entrainment and Mixing in Turbulent Jets," American Institute of Aeronautics and Astronautics Journal 25 (9):1216-1223, 1987.

[15] Philip, J. and Marusic, I., "Large-Scale Eddies and Their Role in Entrainment in Turbulent Jets and Wakes," Physics of Fluids 24, 2012.

[16] Hu, B., Musculus, Mark P B, and Oefelein, J.C., "The Influence of Large-Scale Structures on Entrainment in a Decelerating Transient Turbulent Jet Revealed by Large Eddy Simulation,' Physics of Fluids 24, 2012.

[17] Townsend, A.A., "Entrainment and the structure of turbulent flow," Journal of Fluid Mechanics 41:13-46, 1970.

[18] Westerweel, J., Fukushima, C., Pedersen, J.M., and Hunt, J C R, "Momentum and Scalar Transport at the Turbulent/Non-
Turbulent Interface of a Jet," Journal of Fluid Mechanics 631:199-230, 2009.

[19] Mathew, J. and Basu, A.J., "Some Characteristics of Entrainment at a Cylindrical Turbulence Boundary," Physics of Fluids 14 (7):2065-2072, 2002.

[20] Cao, Z., Nishino, K., Mizumo, S., and Torii, K., "PIV measurement of internal structure of Diesel fuel spray," Experiments in Fluids:211-219, 2000.

[21] Schefer, R.W. and Kerstein, A.R., "Role of Large-Scale Structures in a Non-Reacting Turbulent CH4 Jet," Physics of Fluids 6 (2):652-661, 1994.

[22] Pastor, J.V., Javier López, J., García, J.M., and Pastor, J.M., “A 1D model for the description of mixing-controlled inert diesel sprays," Fuel 87(13-14):2871-2885, 2008, doi:10.1016/j.fuel.2008.04.017.

[23] Naber, J. and Siebers, D.L., "Effects of Gas Density and Vaporization on Penetration and Dispersion of Diesel Sprays," SAE Technical Paper 960034, 1996.

[24] Bruneaux, G., Causse, M., and Omrane, A., "Air Entrainment in Diesel-Like Gas Jet by Simultaneous Flow Velocity and Fuel Concentration Measurements, Comparison of Free and Wall Impinging Jet Configurations," SAE International Journal of Engines 5(2)(2011-01-1828):76-93, 2011.

[25] Pickett, L.M., Genzale, C.L., Bruneaux, G., Malbec, L.-M. et al., "Comparison of Diesel Spray Combustion in Different High-Temperature, High-Pressure Facilities," SAE Technical Paper 2010-01-2106, 2010.

[26] Meijer, M., Somers, B., Johnson, J., Naber, J. et al., "Engine Combustion Network (ECN): Characterization And Comparison Of Boundary Conditions For Different Combustion Vessels," Atomization and Sprays 22 (9):777-806, 2012.

[27] Meijer, M., Malbec, L.-M., Bruneaux, G., and Somers, L M T, "Engine Combustion Network: "Spray A" basic measurements and advanced diagnostics," ICLASS 2-6 Sept. 2012, Heidelberg, Germany, 2012

[28] Bardi, M., Payri, R., Malbec, L.-M., Bruneaux, G. et al., "Engine Combustion Network: Comparison Of Spray Development, Vaporization, And Combustion In Different Combustion Vessels," Atomization and Sprays 22 (10):807$842,2012$.

[29] Pickett, L.M., Manin, J., Genzale, C.L., Siebers, D.L. et al., "Relationship Between Diesel Fuel Spray Vapor Penetration/Dispersion and Local Fuel Mixture Fraction," SAE Technical Paper 2011-01-0686, 2011.

[30] Desantes, J.M., Pastor, J.V., García-Oliver, J.M., and Pastor, J.M., "A 1D model for the description of mixing-controlled reacting diesel sprays," Combustion and Flame 156(1):234249, 2009, doi:10.1016/j.combustflame.2008.10.008.

[31] Kastengren, A.L., Tilocco, F.Z., Powell, C.F., Manin, J. et al., "Engine Combustion Network (ECN): Measurements of Nozzle Geometry and Hydraulic Behavior," Atomization and Sprays 22 (12):1011-1052, 2012.

[32] Bardi, M., Bruneaux, G., and Malbec, L.-M., "Study of ECN Injectors' Behavior Repeatability with Focus on Aging Effect and Soot Fluctuations," SAE 2016 World Congress and Exhibition, SAE International, 2016.

[33] Malbec, L.-M. and Bruneaux, G., "Study of Air Entrainment of Multi-hole Diesel Injection by Particle Image Velocimetry Effect of Neighboring Jets Interaction and Transient Behavior After End of Injection," SAE Technical Paper 2010-01-0342, 2010.

[34] Raffel, M., Willert, C.E., Wereley, S., and Kompenhans, J., "Particle Image Velocimetry: A Practical Guide," 2nd ed., Springer-Verlag Berlin Heidelberg, ISBN 978-3-540-72308-0, 2007.

Page 11 of 12 
[35] Abramovich, G.N., "The Theory of Turbulent Jets," 1963.

[36] Basset, A.B., "Treatise on Hydrodynamics, vol. II," Deighton, Bell \& Co, London, 1888

[37] Melling, A., "Tracer particles and seeding for particle image velocimetry," MEASUREMENT SCIENCE \& TECHNOLOGY 8(12):1406-1416, 1997, doi:10.1088/0957-0233/8/12/005.

[38] Mei, R., "Velocity fidelity of flow tracer particles," Experiments in Fluids 22(1):1-13, 1996, doi:10.1007/BF01893300.

[39] Adrian, R.J., "Double Exposure, Multiple-Field Particle Image Velocimetry For Turbulent Probability Density," OPTICS AND LASERS IN ENGINEERING 9(3-4):211-228, 1988, doi:10.1016/S0143-8166(98)90004-5.

[40] Keane, R.D. and Adrian, R.J., "Theory of cross-correlation analysis of PIV images," Applied Scientific Research 49(3):191-215, 1992, doi:10.1007/BF00384623.

[41] Westerweel, J., "On velocity gradients in PIV interrogation," Experiments in Fluids 44(5):831-842, 2008, doi:10.1007/s00348-007-0439-3.

[42] Espey, C., Dec, J.E., Litzinger, T.A., and Santavicca, D.A (eds.), "Quantitative 2-D Fuel Vapor Concentration Imaging in a Firing D.I. Diesel Engine Using Planar Laser-Induced Rayleigh Scattering*," SAE International, 1994.

[43] Idicheria, C.a. and Pickett, L.M., "Quantitative Mixing Measurements in a Vaporizing Diesel Spray by Rayleigh Imaging," SAE Technical Paper 2007-01-0647, 2007, doi:10.4271/2007-01-0647.

[44] Bruneaux, G., "Mixing Process in High Pressure Diesel Jets by Normalized Laser Induced Exciplex Fluorescence - Part II: Wall Impinging Versus Free Jet," SAE Technical Paper 2005 01-2097, 2005.

[45] Malbec, L.-M., Egúsquiza, J., Bruneaux, G., and Meijer, M., "Characterization of a Set of ECN Spray A Injectors: Nozzle to Nozzle Variations and Effect on Spray Characteristics," SAE International Journal of Engines 6 (3):1642-1660, 2013, doi: 10.4271/2013-24-0037.

Page 12 of 12 